\title{
What Confucian Philosophy Means for Chinese and Asian Psychology Today: Indigenous Roots for a Psychology of Social Change
}

\author{
James H. Liu \\ Centre for Applied Cross-Cultural Research, School of Psychology, Victoria University of Wellington, Wellington, New Zealand
}

\begin{abstract}
It is claimed via analysis of Shu-Hsien Liu's seminal book Understanding Confucian Philosophy that contemporary Confucianism offers: (1) a set of ultimate concerns that can be used to guide life and scholarly endeavour; (2) an axiomatic world view, and a generative model of human nature that not only accords with empirical evidence, but is highly adaptive in organising society; (3) an epistemology that is appropriate for social science research on social change. These qualities suggest that contemporary Confucianism can inform psychological research in a manner that goes far deeper than merely describing popular tendencies among culturally Chinese people. It may be used in constructing a form of social science with depth and utility in addressing both practical and existential concerns of scholars and ordinary people in society that is not restricted to Chinese societies alone, but any society in need of inspiration in seeking to construct humanist ethics for research and governance.
\end{abstract}

Keywords: Confucian philosophy, epistemology, values, indigenous psychology, Chinese psychology, philosophy of science, worldviews

The past 35 years have witnessed an explosive growth in Chinese psychology, as indexed by the 41 chapter authors covering 732 pages in Michael Harris Bond's 2010 edition of the Oxford Handbook of Chinese Psychology (compared to 32 chapter authors covering 588 pages in the 1996 Handbook). The topics in the latest edition range from cognitive neuroscience to socialisation of values, language acquisition, personality, gender, and political psychology. In virtually every domain, the Handbook's authors have meticulously documented ways in which culturally Chinese people differ from and (to a lesser extent in terms of focus) are similar to a mainstream psychology based on world-dominant north Americans. Bond (2010) writes, 'Clearly, there has been and continues to be, a considerable demand for intellectual material on the psychology of the Chinese people' (p. 1). The foremost characteristic he lists is 'China's longevity as a coherent cultural tradition' that together with its size results in 'an emerging recognition of China's central role in the management of those global interdependencies that will determine our planetary survival in the twenty-first century' (p. 1).

Culture is the centerpiece of psychology's attempt to understand the unity in diversity of human beings. 'What exactly is culture?' Bond (2010) asks, 'and how does it exercise its impact in molding the lives of those individuals born into that tradition and socialized by its institutions?' (p. 2). For a plurality of the authors in this Handbook, the ultimate answer to this question is clear. 'Confucian philosophy' is the single most indexed topic in Bond's (2010) massive volume, with the 50 entries covering such topics as Confucian approaches to leadership, social identity, parenting, education, and wellbeing exceeding the 40 -some entries devoted to the next most indexed topics, the psychological concept of self, and things to do with Taiwan.

However, in-depth examination reveals that virtually all of the references are to psychologists, or occasionally a sociologist or other social scientist, and almost never to a philosopher. One chapter (Shi \& Feng, 2010) provides a section on tien ren he yi (天人合一) without even mentioning Chu Hsi (Zhu Xi) or the Song-Ming philosophical thinking from whence that term originated. In other words, there is a pervasive but shallow engagement with Confucianism in Chinese psychology. Such shallow foundations cannot sustain the deeper agenda of planetary survival expressed in Bond's opening statement. Nor does it provide roots for an indigenous Chinese psychology

Address for correspondence: Professor James H. Liu, Co-Director, Centre for Applied Cross Cultural Research, Victoria University of Wellington, New Zealand.Email: james.liu@vuw.ac.nz 
capable of simultaneously benefitting locals and enhancing global understanding (J.H. Liu, Ng, Gastardo-Conaco \& Wong, 2008). Of the 41 chapters in the Handbook, only the work of Hwang \& Han (2010; see also Hwang, 2012) is centred in an engagement with Chinese philosophy.

I have been in the fortunate position of having written four articles in collaboration with my father, an eminent Neo-Confucianist, in constructing a culturally appropriate Asian and Chinese psychology (J.H. Liu \& S.H. Liu, 1997, 1998, 1999, 2003). The focus of these articles has been on the epistemology and practice of social psychology: they were seminal thought pieces that have subsequently influenced my leadership strategies as PresidentElect (2011-2013) and President of the Asian Association of Social Psychology (see J.H. Liu \& Ng, 2007). As I have grown older and matured as a scholar, I see the virtue of Confucian philosophy in its own right, both as a guide for living and as an object of research, especially when the object of research is social or personal change. In this respect, although Confucian philosophy is indigenous to China and Chinese societies, and has been most influential historically in East Asia (including Korea and Japan), there have been no barriers to applying its principles to the development of Asian social psychology more generally.

References to Confucian philosophy in Bond's (2010) Handbook were almost all in the domain of what my father calls 'Popular Confucianism': Belief at the grassroots level that emphasises concepts such as 'family values, diligence, and education and can hardly be separated from other beliefs in popular Buddhism and Taoism' (S.H. Liu, 1998, p. 14). But the value of contemporary Confucian philosophy is far greater than this: my father's lifelong mission has been to elucidate 'Spiritual Confucianism': 'The tradition of great thinkers such as Confucius, Mencius, Ch'eng $\mathrm{Chu}$, and Lu-Wang that has been revived by contemporary Neo-Confucians as their ultimate commitment' (S.H. Liu, 1998, p. 13). Confucian philosophy includes ethics and epistemology that can be used to illuminate social science as a humanistic endeavour aimed at social change.

The purpose of this article is to analyse Shu-hsien Liu's (1998) seminal English-language volume Understanding Confucian Philosophy by bringing the civilisational logic it elucidates into deeper dialogue with the prevalent empiricism of Chinese and Asian psychology today. From Understanding Confucian Philosophy, I argue that contemporary Confucianism offers: (1) a set of ultimate concerns that can be used to guide life and scholarly endeavour; (2) an axiomatic world view, and a generative model of human nature that not only accords with empirical evidence, but is highly adaptive in organising society; (3) an epistemology and ethics that is appropriate for social science research. These qualities suggest that contemporary Confucianism can inform psychological research in a manner that goes far deeper than merely describing popular tendencies among culturally Chinese people. It may be used in constructing a form of social science with depth and utility in addressing both practical and existential concerns of scholars and ordinary people in society; that is, a science and practice of social change.

\section{Historical Background}

On the first page of Understanding Confucian Philosophy is a crucial statement: 'The Confucian tradition does not start with Confucius' (S.H. Liu, 1998, p. 3). Confucianism is an 'orthodoxy-conscious tradition' that drew from the civilisational resources that went before it to establish a moral order venerating antiquity. By narrating an historical succession from the Three Sovereigns to the Five Emperors and three dynasties, Confucianism created an orthodoxy based on a conception of the high culture of a distant, semi-mythical past rather than on contemporary rulers or salient ethnicities. This helped make China's historical unity a cultural unity rather than one based on contemporary ethno-nationalism (see J.H. Liu, Li, \& Yue, 2010). This became part of the ruling orthodoxy of imperial China, and was a central element to the endurance of Chinese culture despite long periods of weak/divided states. But such an orthodox Chinese high culture passed away with the Chinese imperial dynasties. Contemporary China is Communist and forward-looking, embracing science and some market-based features of Western modernity. The state uses the past (e.g., aggrieved war memories against Japan; see Liu \& Atsumi, 2008) more in line with contemporary forms of nationalism than in accord with imperial traditions. There has been a rupture (Onar, Liu, \& Woodward, 2014) with the past, where the politicised Confucianism that once managed the bureaucracy and ideology of the imperial state is now dead. Confucianism itself, however, is a living tradition, and it does not have to adhere to elements of its past that are no longer psychologically active today. Grassroots or popular Confucianism fed by a revived spiritual Confucianism can still play an important role in adding vitality to efforts to build a more generative research agenda and a more morally, ethically and community-centred contemporary Chinese society. Furthermore, although popular Confucianism would only be prevalent in Chinese societies (and in East Asia), spiritual Confucianism may play a part in inspiring research agendas in other parts of the world.

\section{Confucianism as a Source of Ultimate Concerns}

The remaining characteristics of Confucianism are highly applicable in today's globalising and modernising world: according to S.H. Liu (1998, pp. 7-8), Confucianism is a morally and socially conscious tradition that is focused on this-worldly concerns and conduct. Elsewhere (J.H. Liu, 2014), I have argued:

Confucianism is a humanist philosophy that has facilitated East Asian peoples to embark on a trajectory towards the market economics of modernity without dissolving critical elements of the traditional moral order. Confucian ethics are relational, reciprocal, and hierarchical, not supernatural. They are based in status differences that are not immutable, but incorporate inequality sourced from both the external mantle of social positions and 
from the internal virtues of self-cultivation (Hwang, 2012a, b). Confucianism offers a form of humanism based on different premises than Western humanism, but its lack of emphasis on the supernatural and its focus on relational ethics that can manage inequality has worked well for East Asian societies in their path towards modernization (Yang, 1998).

My father put it this way:

In effect, Confucianism not only offered a way to solve problems at a time of disorder and disruption; it also furnished a faith different from a religious faith.... What Confucius committed to was an ultimate concern to settle one's body and soul in this life. As he said, 'It is man who can make the Way great, not the Way that can make man great'. (S.H. Liu, 1998, p. 12)

In contrast to Taoism, which focuses on the natural world and people's place in it, Confucianism puts the human world of social and ethical relations at the heart of its philosophy.

The central tenet by which a human being is to develop in a Confucian Way is to practice ren (仁), humanheartedness. The organisation of the Analects is dialogical, and never offers an analytical definition of this crucial concept: as S.H. Liu says, the best way to understand the Analects is to memorise its passages so they can be applied to different situations. Ren includes a differentiated form of love, respect for others and seriousness to one's duties, loyalty, self-mastery, propriety, and benevolence in extending one's inner virtue for the benefit of others (see S.H. Liu, 1998, pp. 17-22). Setting a moral example through propriety is an important part of ren. Benevolence is cultivated, it emerges through the attainment of wisdom:

Precisely because the moral discipline of the self and the seeking of well-being of people cannot be separated, Confucius refuses to draw a sharp line of distinction between moral and political activities.... The highest ideal of a man is ... 'the way of inward sageliness and outward kingliness'. (S.H. Liu, 1998, p. 20)

This idealistic form of political psychology has had a mixed legacy, as it did not provide legal guarantees to protect human rights or expand political participation (see $\mathrm{Ng}$, 2010). Cultivating human-heartedness is essential for good governance by any politician, ruler, or political class, but in reality many of them cultivate just the opposite, while maintaining appearances. Confucian forms of political statecraft focusing on the importance of setting a good moral and ethical example are always vulnerable to Machiavellian capture. The Confucian ideal of inward sageliness and outward kingliness is as rare today as it was in his times: it is more needed than ever, but is extremely difficult to teach and inculcate. How this may be applied to the problem of corruption in contemporary China has massive potential implications and applications, as a formal system of checks and balances administered by law seems difficult for the one-party politics of Communism to implement.
Therefore, the Chinese government has been looking to Singapore for answers, as Singapore is a predominantly Chinese society that has been under one-party (though democratic) rule for half a century, but is the least corrupt society in Asia (according to Transparency International). I summarise Quah's (2001) lessons from Singapore as incorporating a blend of Confucianist and Legalist strategies from Chinese history: (1) political leadership must demonstrate exemplary conduct and punish 'big fish', not just 'little fish' who are corrupt, while increasing salaries and reducing opportunities for corruption for government officials (Confucianist); and (2) an overall anti-corruption strategy must be adopted consisting of comprehensive anti-corruption laws and an autonomous anti-corruption agency that is incorruptible and outside police jurisdiction (Legalist). Whether gigantic China can successfully implement strategies followed by diminutive Singapore remains to be seen, but Chinese President $\mathrm{Xi}$ Jinping's prosecution of former politburo member Zhou Yongkang for corruption certainly signals seriousness of intent.

Where Confucian emphasis on the perfectability of human nature has had a more unambiguously positive legacy is in the domain of education. Confucius was first and foremost a teacher, a cultivator of students. Contemporary psychology has noted how anomalous the superb performance of East Asians is on educational outcomes compared to what might be expected from North American theories (Stevenson, Lee, \& Stigler, 1986; Stevenson \& Stigler, 1992). Kember and Watkins (2010) write that 'school learning environments in most Chinese societies, which have an overemphasis on assessment and teachercentered instruction together with their typically large class sizes, do not conform to Western models of good practice, nevertheless, many Chinese students achieve outstanding results' (p. 176). Chinese (and Japanese) math teachers have been shown to have superior cultural scripts for teaching their topic with greater depth and coherence than in many Western societies. What also consistently comes through is that 'teachers in China and Hong Kong believe they have the role of cultivating not only their students' cognitive development, but also promoting positive attitudes to society and responsible moral behavior' (Kember \& Watkins, 2010, p. 177). They do this implicitly, by cultivating personal relationships with their students, and in alliance with parents, internalising a thirst for learning (Stevenson \& Stigler, 1992).

Students, in turn, do not simply learn by rote, as implied in Western theory about surface versus deep approaches to learning, but rather develop through a sequence of learning through stages, from reproduction to heightened levels of understanding through attentive effort. 'Educational achievement is often emphasized as a social obligation, especially obligation to parents and family ... learning [is] a means for self-cultivation and selfperfection' (p. 190, Hau \& Ho, 2010). Blurring the line between intrinsic (good) and extrinsic (bad) motivation, 
'research findings strongly suggest that behind Chinese students' high academic performance is their willingness to exert effort on tasks of even low interest or under external pressure, a focus that has been attributed to their greater sense of responsibility and value attached to learning' (Hau \& Ho, 2010, p. 192). The major legacy of Confucius as a culture hero for Chinese society is thus anomalously excellent educational achievement, where society's goals become the individual's goals, and what is intrinsic and what is extrinsic in these motivations becomes blurred (see Stevenson \& Stigler, 1992).

In terms of religious philosophy, 'Confucius's great contribution lies not in his giving an answer to the question, but in his refusal to answer the question ... Do spiritual beings exist?' (S.H. Liu, 1998, p. 23). Confucius always advocated participation in religious rites (e.g., sacrifices) without ever affirming the existence of spiritual beings (i.e., deceased ancestors or $\mathrm{god} / \mathrm{s}$ ): 'the real foundation of ritual performances lies deep in the self rather than in the outside world ... there is a profound depth dimension in man, and it is only through the realization of this depth dimension that he is able to develop into a full man' (S.H. Liu, 1998, p. 24). The crux of Confucian religious philosophy is that 'although the existence of gods or spiritual beings is not crucial in Confucius' thought, he does show a great faith in Heaven' (S.H. Liu, 1998, p. 24). 'Heaven is a transcendent creative power working unceasingly in an unobtrusive fashion in the universe.... The character of the ruler is like wind and that of the people is like grass. In whatever direction the wind blows, the grass bends' (S.H. Liu, 1998, p. 27). The power of a great leader works in an unobtrusive manner, through alignment with the Mandate of Heaven: then everything is done without taking overt action, a philosophical position very similar to that adopted by the Taoists. It can be examined empirically via consideration of the workings of beliefs about the benevolence of authority (J.H. Liu et al., 2010).

Confucian philosophy is a holistic philosophy. There are no sharp dividing lines between the sacred and the profane or mundane as in much of Western thinking:

If religion is defined in the narrower sense as a belief in a personal god or spiritual beings, Confucius was not much of a religious man. If, on the other hand, religion is defined in the sense of an ultimate commitment that gives satisfaction to the demands of our inner selves, then Confucius was a deeply religious man. (S.H. Liu, 1998, p. 28)

This attitude towards religion is fundamentally amenable to modernity in a most generative way, being humanist without being atheist. This has been under-researched in terms of its psychological and sociological implications: the search for meaning in contemporary Chinese society is more difficult than ever, and Confucianism is as relevant to this quest as it ever was, especially in a massively materialistic society as Communist China.

The 1958 'Manifesto for Reappraisal of Sinology and Reconstruction of Chinese culture' (Chang, 1957-1962), issued as a clarion call at the nadir of Confucianism, urged world scholars to seek five things from Chinese thought (see also S.H. Liu, 1998, p. 262):

1. The spirit to assert what is here and now and to let everything go [in order for nature to take its own course].

2. All-round and all-embracing understanding or wisdom.

3. A feeling of warmness and compassion.

4. The wisdom of how to perpetuate [one's native] culture.

\section{The attitude that the whole world is like one family.}

From this opening manifesto, Neo-Confucianism has developed a rich body of work articulating spiritual Confucianism as a separate tradition from politicised Confucianism, with deep roots and contemporary relevance. S.H. Liu (2000) in particular has emphasised Confucian Openness:

Confucianism has a dual character. On the one hand, it is a faith or ultimate concern, which has religious import: when Confucians find their Way to be sufficient, there is no longer a need to look for other faiths. On the other hand, as Confucianism is not an organised religion and has an open character and syncretic tendency, it is compatible with other faiths. Thus, a person can declare himself or herself to be a Confucian Catholic, a Confucian Protestant, or a Confucian Muslim. Neither need a Confucian be an ethnic Chinese, as is evidenced by the so-called Boston Confucians ...

Thus, even though Neo-Confucian philosophers firmly believe they have given the best expression of their ultimate concern in sheng (creativity) or jen (humanity), theirs is still just one manifestation among others of the transcendent li-i (one principle). They are not in a position to deny that others may give very different expressions to creativity or humanity, or that they may even merge them with other ultimate concerns. Hence the principle to which Neo-Confucian philosophers aspire need not be confined to the Confucian tradition alone.... in China the Confucian message has always been open to all. In this respect Confucianism is leading the way, and the doctrine of li-i-fen-shu (one principle, many manifestations) has left us with rich resources for different religions to live peacefully and harmoniously together in an ever shrinking global village.

\section{Axiomatic Worldviews and a Confucian Model of Human Nature}

Some psychological characteristics of Chinese people cannot be attributed specifically to Confucianism, but more broadly to the cultural milieu wherein the source traditions for Chinese culture developed, including Taoism, Buddhism, and the Yin-Yang schools. The holistic nature of Chinese thinking and feeling has been robustly documented in contemporary psychological research (Ji, Li, \& Guo, 2010; Nisbett, Peng, Choi, \& Norenzayan, 2001). From perception, categorisation, and attribution to emotion regulation, subjective wellbeing, and belief in change, Chinese people have been demonstrated to display patterns of thinking that emphasise: 
contemplation of the entire field.... Objects are defined mainly in terms of their connections with their contexts, whereas knowledge tends to be organized in a thematic and relational fashion.... In short, it is the dynamics among the elements, rather than the elements themselves, that serve as the primary units of analysis in the eyes of holistic thinkers. (Ji, Lee, \& Guo, 2010, p. 156)

A research program to pursue such an approach as methodological relationalism has been outlined by Ho and colleagues (Ho, Peng, Lai, \& Chan, 2001; Ho \& Chau, 2009). Such holistic thinking is strongly emblematic of the approach to Confucian Openness espoused by Shu-hsien Liu above, and situates Confucian modes of thinking like zhongyong (中庸)within broader strands of Chinese civilization (see Cheung et al., 2003).

However, following Confucius, Mencius developed a model of human nature that is more specific to Confucian philosophy, which emerged in argumentation against alternative traditions in The Book of Mencius. 'Mencius was the first in the Confucian school to assert that human nature is good' (S.H. Liu, 1998, p. 34). He refused to accept the seemingly obvious assertion that the desire for food and sex is inborn whereas the desire for righteousness must be learned from external inputs. Mencius took a more sophisticated cultural interactionist position that is today accepted in much of evolutionary science, where evidence that genetic expressions are strongly influenced by context is overwhelming:

External factors provide only the conditions for us to react; the truly determining factor must still lie within ... for Mencius, what is proper to man lies in his ability to reflect and his capacity to practice humanity and righteousness in actual life. Although the endowments of all men are the same, their existential decisions may make a world of difference. (S.H. Liu, 1998, p. 36)

Mencius' theory of Four Beginnings furnishes an indigenous psychological model of motivation and emotion impacting on the development of ethics and morality, factors strongly implicated in any directed program of social change. A feeling of commiseration (or empathy) is the beginning of human-heartedness (ren: 仁), the feeling of shame and dislike is the beginning righteousness (yi: 义), the feeling of deference and compliance is the beginning of propriety (li: 礼), and the feeling of right and wrong is the beginning of wisdom (zhi: 智).

\footnotetext{
'Humanity, righteousness, propriety, and wisdom are not drilled into us from outside,' Mencius argues, 'We originally have them with us. Only we do not think [to find them]. Therefore it is said, "Seek and you will find it, neglect and you will lose it". (p. 39, S.H. Liu, 1998).
}

In sharp contrast to Western psychology, Mencius hypothesises that feelings of deference and compliance and feelings of right and wrong are innate endowments for human nature (see J.H. Liu et al., 2010 for an extended discussion of the nature of hierarchy in Chinese society). These would not be regarded technically as feelings or emotions in Western psychological science, but are central to a Chinese conception of human beings endowed with an original heart/mind that can be cultivated with discernment. In the words of Mou (1979), ren yi neizai, xing you xin xian (仁义内在, 性由心显), or 'humanity and righteousness are internal and human nature is manifested by heart/mind'). Mencius' style of argumentation throughout his dialogues is through metaphors illustrating what contemporary social scientists might describe as a constructionist epistemology that puts small faith in 'pure' description, but sees 'objective reality' as infused with what Mou (1979) described as 'moral subjectivity'. The Chinese worldview is not dictated by epistemological principles born out of a fusion of Christian religion with Greek philosophy. It does not privilege a worldview based on analytical thinking and essentialised categories separating the sacred from the profane. The implications of these different worldviews that inspire alternative readings of reality have not been fully explored, but could be the focus of a Chinese indigenous psychology (see Hwang, 2012) or, more broadly speaking, an Asian social psychology (Liu \& Liu, 1997, 1999, 2003) built around understanding the nature of social change in human societies and organisations. It contains a naturalism that is entirely human, and that is its saving grace.

The proper place of empiricism in such an endeavour is difficult to pin down. But Mencius' point of view is indispensable for what S.H. Liu (1993) described as a 'height psychology', an indigenous Chinese psychology of moral and ethical aspiration rather than a Western psychology of 'pure' empiricism. Mencius summarised his philosophy as follows, in what S.H. Liu (1998) described as perhaps the most important statement of his career: 'He who exerts his mind to the utmost knows his nature. He who knows his nature knows Heaven. To preserve one's mind and to nourish one's nature is the way to serve Heaven' (p. 43). Mencius' point of view is impossible to reduce to the premises of Western psychological science because its basic premises, as described by S.H. Liu (1998), are different:

\begin{abstract}
Heaven does have a will _ only it is manifested through people's likes and dislikes. Mencius has established a unique pattern to link what is transcendent and what is immanent. We do not find any idea or practice like the Sabbath Day in the Chinese culture. There is no gap between the sacred and the profane, the natural and the supernatural, religious and secular activities. It is only man who has the heart-mind that cannot bear to see the suffering of others.... Our ultimate commitment is to humanity and righteousness within us, and yet the realization of what is proper to man helps him to transcend his own limit so that he can identify with the entire universe. ( $p .44)$
\end{abstract}

\section{Epistemology for the Social Sciences}

My father and I have argued consistently (Liu \& Liu, 1997, 1998, 1999, 2003) that Confucian philosophy, and many of the elements it shares with other Chinese and other Asian philosophies, is eminently suitable for developing an epistemology and practice ideal for the social sciences. 
Kashima (2005) has argued that contemporary epistemological struggles in academia between hermeneutic and empiricist schools of thought are located within a Western dualist ontology that separates mind from matter, and human nature from material nature. He claims that:

\section{If we take a view that intentionality is materially realized, mean- ing is part of a causal chain, and social scientific investigation is also part of complex causal processes, we can adopt a monist ontology, in which human nature is not distinct from, but con- tinuous with, material nature. (p. 35)}

This monist ontology takes the form of a philosophy of interconnectedness (Liu \& Liu, 1999; S.H. Liu, 1989) as articulated in the previous sections.

J.H. Liu (2011) followed by arguing:

As most social scientists are not philosophically trained, they have a tendency to translate their cultural ontology into an almost religious commitment on methodological issues that might be described by philosophers as 'methodolatry': the conflation of ontological issues with methodology. As Tillich (1951) observes, value must have an ontological basis. The value of scientific observations formalizing sensible intuition compared to the phenomenology and hermeneutics of intuitive illumination cannot be reduced to any formula involving emotive responses or subjective utilities, and cannot be deduced or induced by any form of logical or empirical proof. Hence, to privilege one set of research practices that are derived from a particular value system associated with a particular ontology as providing 'the answer' to all the social sciences' contributions to the human condition is methodolatry ... In practical terms, this means that Asian traditions do not privilege scientific methods of observation above the intuitive illumination of the original mind but rather see these as complementary forms of knowing. (p. 217)

The metaphysical elements of Confucian philosophy were thought through (though not presented in a formal manner) by Chu-Hi (Zhu Xi) and other Song dynasty philosophers. In Chu-Hsi's system, there is a single creative principle that underlies all of reality, and it is strongly correlated with the human heart-mind:

\begin{abstract}
Heaven is the creative source of all things. In the evolutionary process there emerges the human species. The human mind has the ability to comprehend the heavenly mind because it correlates with the same principle or principles inherent in it. There are disruptions in the great nature as there are disruptions in the human world. Evils in the world are a matter of fact due to malfunctioning of material force, as principle or principles are always good. The crux of the matter lies in whether material force can be induced to work according to principles. On the human level, it is the decision and understanding of the conscious human mind that could make a world of difference. (S.H. Liu, 1998, p. 161)
\end{abstract}

In accord with this position, later Neo-Confucian philosophers like Mou (1979) could allow for the possibility of the 'intuitive illumination' of the cognitive mind (i.e., enlightenment in the highest sense), whereas a Western philosopher steeped in Christian ontology (with a transcendent God) like Kant allowed only sensible intuition: in Western traditions after Kant, the highest form of illumination can never be identified via empirical observation, yet God exists. This results in a dualist ontology that permeates the Western academy (Kashima, 2005). J.H. Liu (2011) argued that a cultural ontology of dualism operating at the implicit level will result in dualist epistemologies and dualist methodologies that either reduce human behaviour to the product of mechanical actions predetermined by social and biological forces, or valorise it to the level of a political endeavour ruled by subjective moralities whose job is to criticise or deconstruct some unjust power establishment. The creativity of Heaven working unceasingly to enlighten and cultivate benevolence in humanity is riven asunder, and academic endeavour is either to reveal the workings of a machine or to deconstruct this machine and expose the system working it as a fraud.

Fundamentally, a Neo-Confucian position on the epistemology and practice of the social sciences knits together these divides by emphasising on the one hand reality constraints - there is no denying the pain of external reality for Confucianism, as neither Confucius nor Mencius ever fulfilled their youthful hearts' desires to advise a king to rule by cultivating a higher morality. On the other hand, there is an unbending faith in humanity as capable of learning to do more with its endowments than past evidence would suggest likely. Confucianism has never surrendered its ideal of rendering leaders blessed with both 'inward sageliness and outward kingliness', even as its efforts most often met with failure. Only in the domain of education have Chinese and other East Asian societies historically influenced by Chinese civilisation been able to achieve learnings that have been unprecedented in the transition from tradition to modernity for non-Western peoples (J.H. Liu, 2014).

In the 21st century, Confucian philosophers have begun the effort to fuse their own cultural modalities with the achievements of other civilisations, so there can be Confucian Catholics, Confucian Protestants, or Confucian Muslims. This practice of unceasing creativity is part of the workings of Heavenly principles, and a legitimate part of the sphere of social science inquiry building from our human endowment for goodness according to the Confucian model of humanity. It behooves social scientists and philosophers to explore these possibilities more fully, as insiders seeking to strengthen Chinese indigenous psychology, as outsiders seeking to expand the humanising activities of psychological science, or anything in between. According to Confucian philosophy, these endeavours can all be interconnected as a work in progress (Liu \& Liu, 1999).

As the great sage himself once remarked:

\begin{abstract}
At fifteen my mind was set on learning. At thirty my character had been formed. At forty I had no more perplexities. At fifty I knew the Mandate of Heaven [天命]. At sixty I was at ease with whatever I heard. At seventy I could follow my heart's desire without transgressing moral principles. (S.H. Liu, 1998, p. 21)
\end{abstract}

In the life span of institutions, I wonder where psychology is, and where Chinese indigenous psychology is? More 
than this, I wonder how a deeper engagement with philosophy might stimulate the growth and maturation of psychology, first to bridge the divide between empiricist and hermeneutical modes of inquiry, and then to vision social sciences capable of using both modes of inquiry to address deeper, if not ultimate concerns, such as the direction of social change in Asian societies. This is the intellectual legacy that my father has given me, as a Chinese, as an Asian, as an American, as a New Zealander, and as a global social psychologist. My hope is that this legacy can be useful to social psychologists in the Asia-Pacific who are trying to construct a new means of doing research that engages self in society, for the betterment of both.

\section{References}

Bond, M.H. (Ed). (2010). Oxford handbook of Chinese psychology. Oxford: Oxford University Press.

Chang, C. (1957-1962). The development of Neo-Confucian thought. New York: Bookman Associates.

Cheung, T.S., Chan, H.M., Chan, K.M., King, A.Y.C, Chiu, C.Y., \& Yang, C.F. (2003). On Zhongyong rationality: The Confucian doctrine of the mean as a missing link between instrumental rationality and communicative rationality. Asian Journal of Social Psychology, 31(1), 107-127.

Hau, K.T., \& Ho, I.T. (2010). Chinese students' motivation and achievement. In M.H. Bond (Ed.), Oxford handbook of Chinese psychology (2nd ed., pp. 187-204). Oxford: Oxford University Press.

Ho, D.Y.F., \& Chau, A.W.L. (2009). Interpersonal perceptions and metaperceptions of relationship closeness, satisfaction and popularity: A relational and directional analysis. Asian Journal of Social Psychology, 12, 173-184.

Ho, D.Y.F., Peng, S.Q., Lai, A.C., \& Chan, S.F.F. (2001). Indigenization and beyond: Methodological relationalism in the study of personality across cultural traditions. Journal of Personality, 69(6), 925-953.

Hwang, K.K. (2012). Foundations of Chinese psychology: Confucian social relations. New York: Springer.

Hwang, K.K., \& Han, K.H. (2010). Face and morality in Confucian society. In M.H. Bond (Ed.), Oxford handbook of Chinese psychology (2nd ed., pp. 479-498). Oxford: Oxford University Press

Ji, L.J., Lee, A., \& Guo, T. (2010). The thinking styles of Chinese people. In M.H. Bond (Ed.), Oxford handbook of Chinese psychology (2nd ed., pp. 155-167). Oxford: Oxford University Press

Kashima, Y. (2005). Is culture a problem for social psychology? Asian Journal of Social Psychology, 8, 19-38.

Kember, D., \& Watkins, D. (2010). Approaches to teaching and learning by the Chinese. In M.H. Bond (Ed.), Oxford handbook of Chinese psychology (2nd ed., pp. 169-186). Oxford: Oxford University Press.

Liu, J.H. (2011). Asian epistemologies and contemporary social psychological research. In N. Denzin \& Y. Lincoln (Eds.), Handbook of qualitative research (4th ed., pp. 213-226). Thousand Oaks, CA: Sage.
Liu, J.H. (2014). Globalizing indigenous psychology: An East Asian form of hierarchical relationalism with worldwide implications. Journal for the Theory of Social Behavior. Published online 6 March 2014, doi:10.1111/jtsb.12058.

Liu, J.H., \& Atsumi, T. (2008). Historical conflict and resolution between Japan and China: Developing and applying a narrative theory of history and identity. In T. Sugiman, K.J. Gergen, W. Wagner, \& Y. Yamada (Eds.), Meaning in action: Constructions, narratives, and representations (pp. 327-344). Tokyo: Springer-Verlag.

Liu, J.H., Li, M.C., \& Yue, X.D. (2010). Chinese social identity and intergroup relations: The influence of benevolent authority. In M.H. Bond (Ed.), Oxford Handbook of Chinese Psychology (2nd ed., pp. 579-597). Oxford: Oxford University Press.

Liu, J.H., \& Liu, S.H. (1997). Modernism, postmodernism, and Neo-Confucian thinking: A critical history of paradigm shifts and values in academic psychology. New Ideas in Psychology, 15(2), 159-177.

Liu, S.H., \& Liu, J.H. (1998). Confucian philosophy and psychology: A summary of interrelations. In K.S. Yang (Ed.), Indigenous psychological research in Chinese societies (本土心理學研究), [in Chinese] (pp. 343-364). Taipei: Gui Kuan Books, National Taiwan University.

Liu, J.H., \& Liu, S.H. (1999). Interconnectedness and Asian social psychology. In T. Sugiman, M. Karasawa, J.H. Liu, \& C. Ward (Eds.), Progress in Asian Social Psychology (vol. 2, pp. 9-31). Seoul: Kyoyook Kwahaksa,

Liu, J.H., \& Liu, S.H. (2003). The role of the social psychologist in the 'Benevolent Authority' and 'Plurality of Powers' systems of historical affordance for authority. In K.S. Yang, K.K. Hwang, P.B. Pedersen, \& I. Daibo (Eds.), Progress in Asian social psychology: Conceptual and empirical contributions (vol. 3, pp. 43-66). Westport, CT: Praeger.

Liu, J.H., \& Ng, S.H. (2007). Connecting Asians in global perspective: Special issue on past contributions, current status, and future prospects of Asian social psychology. Asian Journal of Social Psychology, 10(1), 1-7.

Liu, J.H., Ng, S.H., Gastardo-Conaco, C., \& Wong, D.S.W.(2008). Action research: A missing component in the emergence of social and cross-cultural psychology as a fully interconnected global enterprise. Social \& Personality Psychology Compass, 2(3), 1162-1181

Liu, S.H. (1989). Toward a new relation between humanity and nature: Reconstructing t'ien-jen-ho-i. Zygon, 24, 457468.

Liu, S.H. (1993). The psychotherapeutic function of the Confucian discipline of Hsin (mind-heart). In L.Y. Cheng, F. Cheung, \& C.N. Chen (Eds.) Psychotherapy for the Chinese (pp. 1-17). Hong Kong: Chinese University of Hong Kong.

Liu, S.H. (1998). Understanding Confucian Philosophy: Classical and Sung-Ming. Westport, CT: Greenwood.

Liu, S.H. (2000). The openness of Confucianism. Global Dialogues, 2(1). Retrieved from http://www.worlddialogue. org/content.php?id=62

Mou, Z.S. (1979). Unique features of Chinese philosophy. Taipei, Taiwan: Xuesheng Shuju. 
Ng, I. (2010). Chinese political psychology: Political participation in Chinese societies. In M.H. Bond (Ed.), Oxford handbook of Chinese psychology (2nd ed., pp. 563-578). Oxford: Oxford University Press.

Nisbett, R.E., Peng, K., Choi, I., \& Norenzayan, A. (2001). Culture and systems of thought: Holistic versus analytic cognition. Psychological Review, 108, 291-310.

Onar, N.F., Liu, J.H., \& Woodward, M. (2014). Symbologies, technologies, and identities: Critical Junctures Theory and the multi-layered nation-state. International Journal of Intercultural Relations. Published online 6 November 2014, doi:10.1016/j.ijintrel.2014.08.009

Quah, J.S.T. (2001). Combatting corruption in Singapore: What can be learned? Journal of Contingencies and Crisis Management, 9(1), 29-35.
Shi, X., \& Feng, B. (2010). Chinese cultural psychology and contemporary communication. In M.H. Bond (Ed.), Oxford handbook of Chinese psychology (pp. 555-562). Oxford: Oxford University Press.

Stevenson, H.W., \& Stigler, J.W. (1992). The learning gap: Why our schools are failing and what we can learn from Japanese and Chinese education. New York: Simon \& Schuster.

Stevenson, H.W., Lee, S.Y., \& Stigler, J.W. (1986). Mathematics achievement of Chinese, Japanese, and American children, Science, 231, 693-699.

Tillich, P. (1951). Systematic theology. Chicago: University of Chicago Press.

Yang, K.S. (1998). Chinese responses to modernization: A psychological analysis. Asian Journal of Social Psychology, 1, 7597. 